OPEN ACCESS

Edited by:

Roumen Kirov,

Institute of Neurobiology (BAS),

Bulgaria

Reviewed by:

Emily L. Casanova,

University of South Carolina,

United States

Antonella Trotta,

King's College London,

United Kingdom

Aygun Ertugrul,

Hacettepe University, Turkey

*Correspondence:

Ryota Hashimoto

hashimor@psy.med.osaka-u.ac.jp

Specialty section: This article was submitted to

Psychopathology,

a section of the journal

Frontiers in Psychiatry

Received: 06 October 2017 Accepted: 11 December 2017 Published: 22 December 2017

Citation:

Ohi K, Sumiyoshi C, Fujino $H$, Yasuda Y, Yamamori $H$, Fujimoto $M$,

Sumiyoshi T and Hashimoto $R$ (2017)

A Brief Assessment of Intelligence

Decline in Schizophrenia As

Represented by the Difference between Current and Premorbid Intellectual Quotient.

Front. Psychiatry 8:293.

doi: 10.3389/fpsyt.2017.00293

\section{A Brief Assessment of Intelligence Decline in Schizophrenia As Represented by the Difference between Current and Premorbid Intellectual Quotient}

\author{
Kazutaka Ohi', Chika Sumiyoshi' ${ }^{2}$, Haruo Fujino ${ }^{3}$, Yuka Yasuda4, Hidenaga Yamamori", \\ Michiko Fujimoto ${ }^{4}$, Tomiki Sumiyoshi ${ }^{5}$ and Ryota Hashimoto ${ }^{4,6 *}$
}

${ }^{1}$ Department of Neuropsychiatry, Kanazawa Medical University, Uchinada, Japan, ${ }^{2}$ Faculty of Human Development and Culture, Fukushima University, Fukushima, Japan, ${ }^{3}$ Graduate School of Education, Oita University, Oita, Japan, ${ }^{4}$ Department of Psychiatry, Osaka University Graduate School of Medicine, Suita, Japan, ${ }^{5}$ Department of Clinical Epidemiology, Translational Medical Center, National Center of Neurology and Psychiatry, Kodaira, Japan, ${ }^{6}$ Molecular Research Center for Children's Mental Development, United Graduate School of Child Development, Osaka University, Suita, Japan

Patients with schizophrenia elicit several clinical features, such as psychotic symptoms, cognitive impairment, and subtle decline of intelligence. The latter two features become evident around the onset of the illness, although they may exist even before the disease onset in a substantial proportion of cases. Here, we review the literature concerning intelligence decline (ID) during the progression of schizophrenia. ID can be estimated by comparing premorbid and current intellectual quotient $(\mathrm{IQ})$ by means of the Adult Reading Test and Wechsler Adult Intelligence Scale (WAIS), respectively. For the purpose of brief assessment, we have recently developed the WAIS-Short Form, which consists of Similarities and Symbol Search and well reflects functional outcomes. According to the degree of ID, patients were classified into three distinct subgroups; deteriorated, preserved, and compromised groups. Patients who show deteriorated IQ (deteriorated group) elicit ID from a premorbid level ( $\geq 10$-point difference between current and premorbid IQ), while patients who show preserved or compromised IQ do not show such decline (<10-point difference). Furthermore, the latter patients were divided into patients with preserved and compromised IQ based on an estimated premorbid IQ score >90 or below 90, respectively. We have recently shown the distribution of ID in a large cohort of schizophrenia patients. Consistent with previous studies, approximately $30 \%$ of schizophrenia patients had a decline of less than 10 points, i.e., normal intellectual performance. In contrast, approximately $70 \%$ of patients showed deterioration of IQ. These results indicate that there is a subgroup of schizophrenia patients who have mild or minimal intellectual deficits, following the onset of the disorder. Therefore, a careful assessment of ID is important in identifying appropriate interventions, including medications, cognitive remediation, and social/community services.

Keywords: schizophrenia, intelligence decline, premorbid intellectual quotient, current intellectual quotient, Wechsler Adult Intelligence Scale 


\section{INTELLIGENCE DECLINE (ID) IN SCHIZOPHRENIA}

Schizophrenia is a common and complex psychiatric disorder with clinical and genetic heterogeneity (1). The lifetime risk of the disorder is approximately $0.5-1 \%$ (2). The disorder is characterized by a wide spectrum of symptoms, such as delusions, hallucinations, blunted affect and withdrawal, cognitive impairments, as well as subtle decline in intelligence. Cognitive impairments in numerous and diverse domains, including attention, working, verbal and visual memories, processing speed, social cognition, and general intelligence (i.e., a 1- to 2-SD decline in performance on neuropsychological tests compared with healthy individuals), are a core feature of the disorder and a reasonable target for treatment (3-9). These deficits contribute to social or occupational dysfunction and poor life outcomes (10-12). Cognitive impairments and psychotic symptoms are relatively independent dimensions of the disorder (13). Cognitive impairments are exhibited around or after the onset of schizophrenia, while, in a substantial proportion of cases, the impairments exist even before the disease onset (14-16). On the other hand, intelligence decline (ID) represents intra-individual differences in intellectual quotinent (IQ) at different time points, such as before and after the onset of morbidity $(13,17,18)$. In this article, we review the literature concerning ID during the progression of schizophrenia.

\section{A BRIEF ASSESSMENT OF ID IN SCHIZOPHRENIA}

Intelligence decline is defined as a decrease in current intellectual quotient (IQ) from a premorbid level in patients with schizophrenia $(13,17,18)$. ID can be estimated by comparing standard assessments of estimated premorbid and current IQ using the Adult Reading Test and the Wechsler Adult Intelligence
Scale (WAIS), respectively. The WAIS has been widely used to measure current intellectual performance in patients with psychiatric disorders as well as healthy subjects. The battery has been updated several times [WAIS (19); WAIS-R (20); WAIS-III (21); and WAIS-IV (22)]. To represent the intellectual construct in a healthy subjects, the four factors, Verbal Comprehension (VC), Working Memory (WM), Perceptual Organization (PO), and Processing Speed (PS), were established in the WAIS-III (Figure 1). VC and WM are components of verbal IQ (VIQ), while PO and PS are components of performance IQ (PIQ). In the updated WAIS-IV, the dual IQ (VIQ and PIQ) scoring system was eliminated, and the concept of index-based assessment of intelligence has been further enhanced. Furthermore, two subtests (Object Assembly and Picture Arrangement and) in the WAIS-III were replaced by newer subtests (Figure Weights and Visual Puzzles) in the WAIS-IV to enhance psychometric validity and user friendliness (23).

It takes $60-95 \mathrm{~min}$ to administrate the WAIS in healthy subjects. As it has been concerned about the lengthy administration time for the WAIS, it has been made efforts to develop the WAIS-Short Form (WAIS-SF) (23-26). The typical approach to developing the WAIS-SF was to select subtests to optimize the prediction of full-scale IQ (FIQ) and/or retain the representativeness of the IQ structure (26). However, it is presumed that the four-factor structure for healthy subjects does not need to be preserved in patients with schizophrenia $(23,26)$; e.g., if VC and WM were collapsed into a single factor in patients with schizophrenia, selecting a subtest from each of these domains would be redundant (26). Another problem for previous WAIS-SFs is the lack of association with real-world outcomes. The WAIS-SF for schizophrenia would be more useful if it reflected functional outcomes, such as activities of daily living or social functioning.

We have recently developed an optimal WAIS-III SF to assess current intellectual performance in patients with schizophrenia (23) according to the following five criteria: (i) prediction of FIQ,

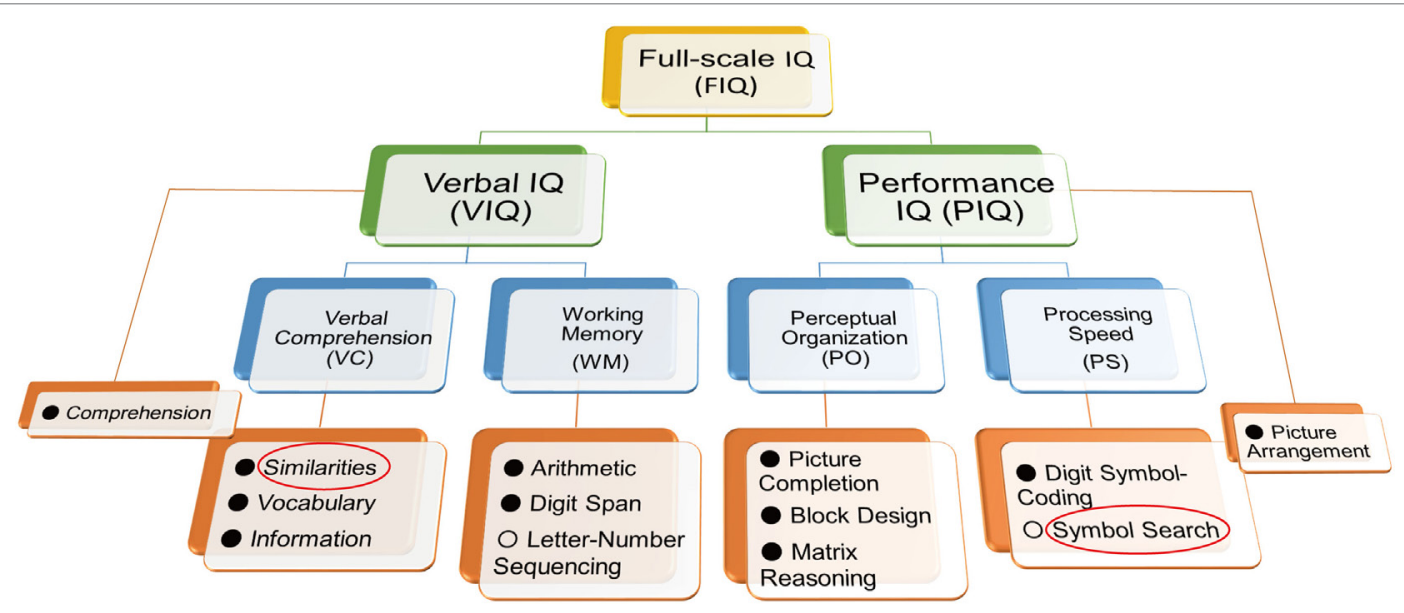

FIGURE 1 | Structure of the Wechsler Adult Intelligence Scale (WAIS)-III. To shorten administration time and assess functional outcome in patients with schizophrenia, we previously developed the WAIS-III Short Form using the Similarities and Symbol Search components (red circles) (23). The administration time was shortened to approximately 10 min. Letter-Number Sequencing and Symbol Search $(\mathrm{O})$ are not used for calculation of verbal intellectual quotient (VIQ) and performance intellectual quotient (PIQ), respectively. 
(ii) representativeness of the IQ structure, (iii) consistency of subtests across versions (WAIS-III and IV), (iv) relation to functional outcomes (daily living skills and social functioning) assessed by the UCSD Performance-based Skills Assessment [UPSA; (27)] and the Social Functioning Scale [SFS; $(28,29)]$, and (v) conciseness in terms of administration time. To select subtests meeting (i) and (ii) criteria, we first conducted an exploratory factor and multiple regression analyses in patients with schizophrenia, and candidate subtests were nominated to produce a candidate SF. The coverage of VIQ and PIQ and the consistency of subtests across WAIS versions, according to (iii) criterion, were also considered in the nomination process. In terms of ability to explain the variance of FIQ, correlations with functional outcomes, and time saved in comparison to full administration of the WAIS, the candidate SFs were finally examined. We found that the dyad of Similarities from verbal intellectual ability and Symbol Search from performance intellectual ability showed the highest correlations with functional outcomes and allowed the shortest administration time (Figure 1). It takes approximately $10 \mathrm{~min}$ to administer the WAIS-SF (Similarities and Symbol Search). It is considered that variation in processing speed is the basis of individual differences in intellectual function (13). In addition, slow cognitive processing in patients with schizophrenia is essential to the clinical manifestation of the disorder (30). Symbol Search is a constituent of the PS factor of the WAIS (Figure 1); therefore, this item is useful on the WAIS-SF for schizophrenia.

\section{DISTRIBUTION OF ID IN SCHIZOPHRENIA}

The National Adult Reading Test (NART), the Wechsler Test of Adult Reading (WTAR), and the Wide Range Achievement Test (WRAT) scores are correlated with cognitive ability in healthy subjects, and scores on the NART, the WTAR, and the WRAT had high stability overtime (31-33). The accuracy of IQ estimates using the NART is higher than that using the $\operatorname{WTAR}(31,32)$, and the WTAR is a slightly more reliable test of IQ estimates than the WRAT in a more educated and higher-functioning population (33). The NART, the WTAR, and the WRAT are three tests developed to estimate premorbid IQ because reading ability is measured as relatively intact in patients with schizophrenia (34), and its validity has been confirmed in English-speaking schizophrenia patients $(13,35,36)$. The Japanese version of the NART [JART; (37)] is also widely used for Japanese-speaking patients to estimate premorbid IQ, as an equivalent to the NART $(6,7$, 38-42). The stability of premorbid IQ assessed by the NART in patients with schizophrenia has been prospectively demonstrated in a longitudinal study (43). On the other hand, estimation of premorbid IQ retrospectively by these tests has a limitation. A longitudinal study design allowing long-term follow-up of high risk groups with baseline and follow-up IQ assessments is the only way to eliminate this limitation.

According to the categorization method described in previous studies $(13,44-51)$, patients with schizophrenia are typically classified by degree of ID into three distinct intellectual level subgroups: deteriorated, preserved, and compromised IQ.

(i) Deteriorated IQ: patients who show an ID as measured by a difference of 10 points or more between estimated premorbid and current IQ.

(ii) Preserved IQ: patients with less than a 10-point difference between estimated premorbid and current IQ and with an estimated premorbid IQ score $>90$.

(iii) Compromised IQ: patients with less than a 10-point difference between estimated premorbid and current IQ and with an estimated premorbid IQ below 90 .

The frequencies of preserved, deteriorated, and compromised IQ in patients with schizophrenia are summarized in Table 1 $(13,18,44-51)$. For example, Weickert et al. (44) reported that $25 \%$ were categorized as having preserved IQ, 51\% displayed deteriorated IQ, and 24\% showed compromised IQ among 117 patients with schizophrenia. Badcock et al. (13) reported that $41 \%$ displayed preserved IQ, $43 \%$ were categorized as having deteriorated IQ, and 16\% displayed compromised IQ among the 109 patients with schizophrenia. However, the distribution of ID in patients with schizophrenia was not examined in depth. Thus, we recently reported on the distribution of the ID in a large cohort of 446 patients with schizophrenia (18). Consistent with

TABLE 1 | Frequencies of preserved, deteriorated, and compromised IQ in patients with schizophrenia.

\begin{tabular}{|c|c|c|c|c|c|c|c|}
\hline Study name & $n$ & Preserved IQ & Deteriorated IQ & Compromised IQ & Diagnostic criteria & Participants & $\begin{array}{l}\text { Assessment of } \\
\text { premorbid IQ }\end{array}$ \\
\hline Weickert et al. (44) & 177 & $24.8 \%(29)$ & $51.3 \%(60)$ & $23.9 \%(28)$ & DSM-III-R & SCZ & WRAT \\
\hline Badcock et al. (13) & 109 & $41.3 \%(45)$ & $43.1 \%(47)$ & $15.6 \%(17)$ & DSM-IV or ICD-10 & SCZ & NART \\
\hline Kremen et al. (46) & 80 & $27.5 \%(22)$ & $50.0 \%(40)$ & $22.5 \%(18)$ & DSM-III-R & SCZ & WRAT \\
\hline Potter and Nestor (49) & 73 & $28.8 \%(21)$ & $28.8 \%(21)$ & $42.5 \%(31)$ & DSM-IV & SCZ or SD & WRAT \\
\hline Leeson et al. (47) & 129 & $31.0 \%(40)$ & $44.2 \%(57)$ & $24.8 \%(32)$ & DSM-III-R or ICD-10 & $\begin{array}{l}\text { first-episode SCZ } \\
\text { or SD }\end{array}$ & WTAR \\
\hline Mercado et al. (48) & 149 & $26.8 \%(40)$ & $39.6 \%(59)$ & $33.6 \%(50)$ & DSM-IV & SCZ or SD & $\begin{array}{l}\text { Information subtest of the } \\
\text { WAIS-III }\end{array}$ \\
\hline Ammari et al. (45) & 72 & $44.4 \%(32)$ & $36.1 \%(26)$ & $19.4 \%(14)$ & DSM-IV & SCZ or SD & WRAT \\
\hline Wells et al. (51) & 534 & $29.4 \%(157)$ & $44.8 \%(239)$ & $25.8 \%(138)$ & DSM-IV & SCZ or SD & WTAR \\
\hline Weinberg et al. (50) & 96 & $26.0 \%(25)$ & $62.5 \%(60)$ & $11.5 \%(11)$ & DSM-IV & SCZ or SD & WTAR \\
\hline Fujino et al. (18) & 446 & $27.1 \%(121)$ & $69.3 \%(309)$ & $3.6 \%(16)$ & DSM-IV or ICD-10 & SCZ & JART \\
\hline
\end{tabular}

SCZ, schizophrenia; SD, schizoaffective disorder; WRAT, Wide Range Achievement Test; NART, National Adult Reading Test; WTAR, Wechsler Test of Adult Reading; WAIS, Wechsler Adult Intelligence Scale; JART, Japanese version of the NART; IQ, intellectual quotient. 
previous studies $(13,44-51)$, approximately $30 \%$ of patients with schizophrenia had a decline of less than 10 points, i.e., normal performance. In contrast, approximately $70 \%$ of patients showed deteriorated IQ: a severe decline of 30 points or greater (13.5\%), a moderate decline of $20-30$ points (26.3\%), a mild decline of $15-20$ points $(15.9 \%)$, or a borderline decline of $10-15$ points (13.7\%) (Figure 2). The estimated premorbid IQ in our study (mean $\pm \mathrm{SE}=100.5 \pm 0.5$ ) was higher than those in previous studies [Weickert et al. (44), $97.1 \pm 1.0$ : Badcock et al. (13), $95.0 \pm 0.7$ : Leeson et al. (47), $91.0 \pm 0.7]$. This difference might be derived from the inclusion criteria, by which our study basically excluded schizophrenia patients who had lower estimated premorbid IQ, such as mental retardation (18), i.e., some patients with compromised IQ were initially excluded from the cohort.

\section{A "NEUROPSYCHOLOGICALLY NORMAL" SCHIZOPHRENIA GROUP}

Social/occupational dysfunction that is remarkably below the level achieved prior to the onset is listed as a diagnostic hallmark for schizophrenia in the DSM-IV and 5 criteria (52); however, neuropsychological impairments were not included in the criteria. As mentioned in the above section, no more than approximately $30 \%$ of schizophrenia patients are entirely free of neuropsychological impairments, although there is heterogeneity in this proportion among studies $(13,18,44,46,47,53,54)$. If cognitive impairments are a core feature of schizophrenia, it may be difficult to explain the presence of neuropsychologically normal function in schizophrenia patients who display the full clinical syndrome.

A cluster-analysis approach can group patients on the basis of profiles or patterns of cognitive impairments and produce more homogeneous groupings $(1,55)$, providing an opportunity to classify patients. Cluster-analysis studies of cognitive function

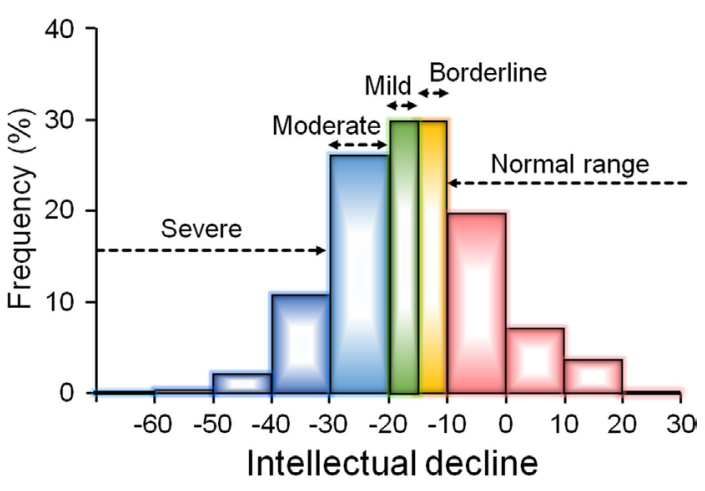

FIGURE 2 | The distribution of intelligence decline (ID) in a large cohort of 446 patients with schizophrenia (18). The article by Fujino et al. (18) is published under the Attribution-Noncommercial-No Derivatives (CC BY-NC-ND) Creative Commons license, and permissions of the modification have been obtained from publisher. Approximately $30 \%$ of patients had no evidence of ID (a decline less than 10 points), while approximately $70 \%$ of patients showed deteriorated intellectual quotient: a borderline decline of 10-15 points (14\%), a mild decline of 15-20 points (16\%), a moderate decline of $20-30$ points $(26 \%)$, or a severe decline of 30 points or greater (14\%) within schizophrenia patients have successfully created meaningful subgroups with at least three clusters: patients who are neuropsychologically normal, patients with intermediate cognitive deficits, and patients with widespread deficits (1,54-60). One consideration is that schizophrenia patients who have mild ID or are neuropsychologically normal may be a unique subtype and may comprise a relatively benign subtype of schizophrenia in terms of prognosis. This type of patient may be better educated and/or have higher premorbid IQ than patients with impaired cognitive function. Indeed, some studies have indicated that patients with preserved IQ tended to be better educated and/ or show higher premorbid IQ than patients with deteriorated or compromised IQ $(13,44,47)$, while other studies have not indicated such associations (46).

On the other hand, schizophrenia patients with preserved IQ exhibited specific deficits in at least some cognitive domains, especially executive function and attention, compared with healthy subjects who had similar IQ, even though that subset of patients had apparently normal current intellectual function $(13,44,53,61,62)$. These studies suggest that ID, although typical of schizophrenia, is not universally characteristic and that executive function and attention deficits may be core features of schizophrenia, independent of intelligence variations (44). However, not only IQ decline but also executive function and attention deficits may be less than universally characteristic of patients with schizophrenia because the disorder is clinically heterogeneous. We suggest that it is necessary to make a detailed, personalized assessment of cognitive impairments, such as IQ decline and executive function and attention deficits, in order to treat functional impairments appropriately in schizophrenia patients. As shown in Figure 3, we additionally suggest an algorithm to be employed in the treatment of intellectual impairments in schizophrenia patients. First, we measure intellectual function in patients with schizophrenia using estimated premorbid and current IQ, and we assess whether the patient has intellectual impairment. According to the status of intellectual impairment, we assess employment-related problems in each patient and treat those problems. The ultimate goal is for the patient to work at a premorbid level.

\section{PATHOPHYSIOLOGY OF COGNITIVE IMPAIRMENTS IN SCHIZOPHRENIA}

Schizophrenia has a strong genetic basis with an estimated heritability of approximately $80 \%$ (63). Most cognitive functions also have a genetic component and are heritable $\left(h^{2}=0.33-0.85\right)$ (64-68). Impairments such as cognitive decline are stable, partly affected by antipsychotic medications (47, 69-71), and typically stronger in schizophrenia patients (72). Cognitive dysfunctions have also been shown in the unaffected relatives or twin siblings of people with schizophrenia (73). Previous genome-wide association studies (GWASs) on schizophrenia and cognitive functions have indicated that many genes or genetic variants mediate both cognitive function and the risk of schizophrenia (7, 17, 73-77). These previous GWASs on schizophrenia and cognitive function have explained up to approximately $20 \%$ 


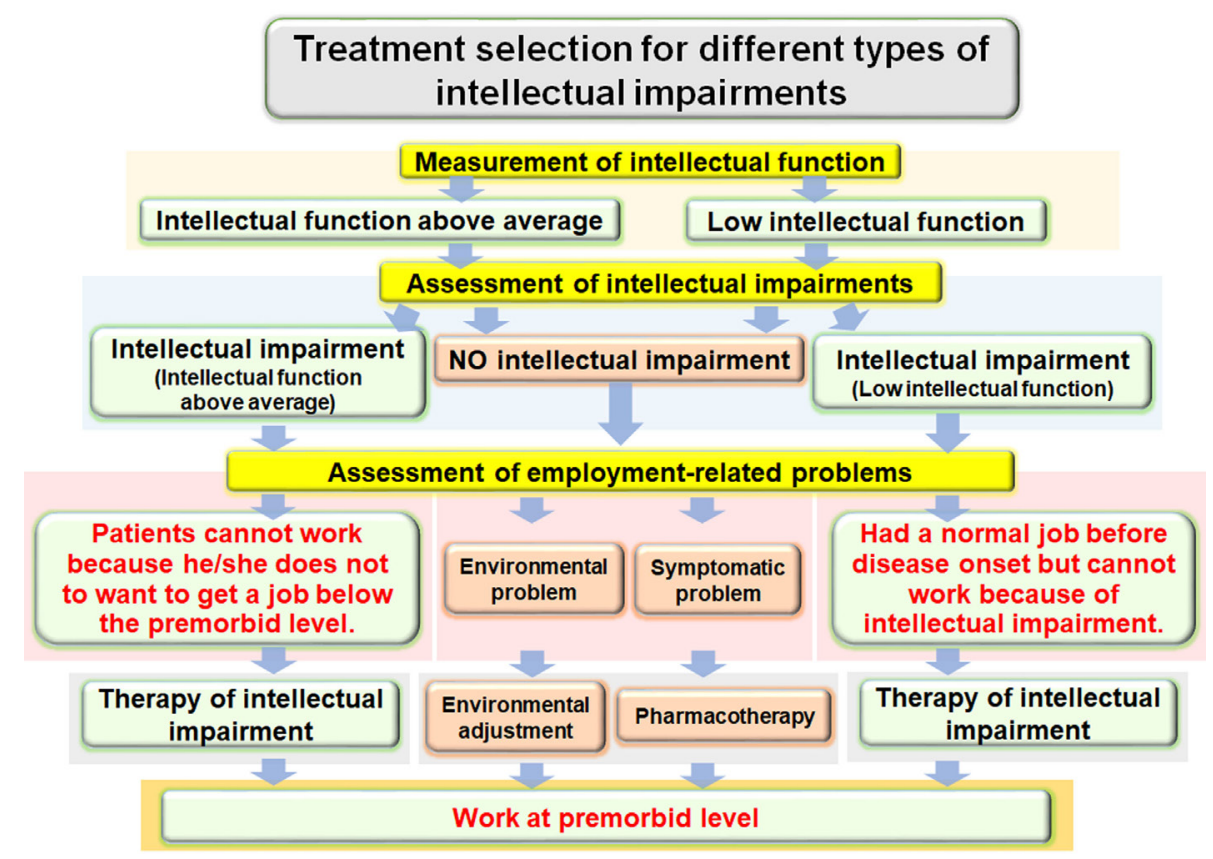

FIGURE 3 | Algorithm for treatment of intellectual impairments in patients with schizophrenia to improve employment outcomes.

of the genetic architecture of risk for schizophrenia and poor cognitive function (74-77). In addition, a part of the phenotypic correlation between cognitive function and schizophrenia results from identical genetic effects $(73,77)$. Polygenic risk scores for cognitive dysfunction were associated with a higher risk of schizophrenia, whereas polygenic risk scores for schizophrenia were associated with lower cognitive ability $(73,77,78)$. Thus, cognitive functions have been proposed as a useful intermediate phenotype $(39,79-82)$ to understand the genetic mechanisms involved in the pathophysiology of schizophrenia.

We suggest that genetic variants related to cognitive impairments including ID might be associated with the $\mathrm{N}$-methylD-aspartate (NMDA) glutamate network (7) or in delta(4)desaturase, sphingolipid 2 (DEGS2) gene expression $(17,83)$. Glutamate is the major excitatory neurotransmitter of the central nervous system (CNS) and is involved in basic neuronal functions and CNS processes, including memory, learning, and synaptic plasticity (84). Decreased function of glutamate transmission through NMDA receptors that are voltage-dependent ionotropic glutamate receptors has been involved in the pathophysiology of schizophrenia (85). NMDA receptor antagonists, including phencyclidine and ketamine, can induce schizophrenia-like psychotic symptoms and cognitive impairments in individuals without schizophrenia and exacerbate symptoms in schizophrenia patients $(86,87)$. Schizophrenia patients have aberrant density and subunit composition of NMDA receptors in the postmortem brains $(88,89)$.

From birth onward, the DEGS2 gene is most abundantly expressed in the dorsolateral prefrontal cortex (DLPFC) that is a major component of the high-order associative cortex related to both schizophrenia and cognitive functions (83,
90). Carriers of the ID-associated risk allele had lower DEGS2 expression than subjects homozygous for the non-risk allele in the DLPFC $(17,83)$. The DEGS2 enzyme is implicated in the biosynthesis of phytosphingolipids. Sphingomyelin is a type of sphingolipid, and abnormalities of the sphingomyelin can cause several CNS diseases, including schizophrenia (91, 92). The low expression pattern of DEGS2 is correlated with the low distribution of phytosphingolipids $(93,94)$. The DEGS2 risk polymorphism related to low DEGS2 expression in the DLPFC may be associated with lower synthesis of sphingolipids in the brain because DEGS2 mRNA expression regulates synthesis of phytosphingolipids during keratinocyte differentiation (93). Further research is needed to clarify the role of glutamate network and DEGS2 gene expression in the pathogenesis of ID of schizophrenia.

\section{EFFECTS OF ANTIPSYCHOTICS ON ID IN SCHIZOPHRENIA}

Positive symptoms and negative symptoms have become targets for medication in patients with schizophrenia. However, based on the evidence that the functional disability accompanying schizophrenia is strongly associated with cognitive impairments and is not correlated with psychotic symptoms (12), we should focus on ID in patients with schizophrenia. The therapeutic effects of antipsychotics are predominantly limited to the positive and negative symptoms, and those drugs have substantially less impact on improvement of cognitive impairments. It has been reported that typical antipsychotics are applied without regard for cognitive impairments in patients with schizophrenia and do little to 
improve them $(84,95)$, whereas atypical antipsychotics have been reported to partly reduce cognitive impairment in schizophrenia patients $(84,95,96)$. Atypical antipsychotics are superior to typical antipsychotics at improving cognitive impairment (effect size $=0.24$ ), although there are no differences in improvement among atypical antipsychotics (97). Such improvements are also observed in specific studies of first-episode schizophrenia and early-onset schizophrenia (98-100).

To date, the mechanisms whereby antipsychotics act on ID have remained unclear. Atypical antipsychotics produce extensive blockade of serotonin $(5-\mathrm{HT})_{2 \mathrm{~A}}$ receptors, direct or indirect stimulation of 5- $\mathrm{HT}_{1 \mathrm{~A}}$ receptors, and, to a lesser extent, a reduction in dopamine D2 receptor-mediated neurotransmission (101-103). The serotonergic actions of the atypical antipsychotics are able to mitigate cognitive impairments in patients with schizophrenia (103). In addition, $5-\mathrm{HT}_{6}$ or $5-\mathrm{HT}_{7}$ receptor antagonists may also contribute to the beneficial effects of the antipsychotics on cognitive function (103).

Furthermore, anticholinergic load is related to lower cognitive function in schizophrenia patients $(104,105)$. The administration rate of anticholinergic medications is lower in patients who are prescribed atypical antipsychotics compared with those who are prescribed typical antipsychotics, supporting the idea that cognitive improvements would differ between users of typical and atypical antipsychotics. The discontinuation of long-term anticholinergic use would mitigate cognitive impairment in patients with schizophrenia $(105,106)$. In addition, the use of benzodiazepines is related to cognitive impairments in schizophrenia patients $(107,108)$. The reduction or discontinuation of long-term benzodiazepines with atypical antipsychotics ameliorates cognitive impairments in patients with schizophrenia (108). These findings suggest that the use of anticholinergics and long-term benzodiazepines would be related to cognitive impairments in patients with schizophrenia. Therefore, we suggest that physicians should prescribe only atypical antipsychotics, without anticholinergics or benzodiazepines, to reduce the cognitive impairments observed in schizophrenia. On the other hand, the use of benzodiazepines and anticholinergics would treat unwanted symptoms, such as anxiety and extrapyramidal symptoms, in schizophrenia. The development of novel antipsychotics that are unlikely to result in extrapyramidal symptom or treat anxiety symptom is warranted.

The cognitive impairments observed in schizophrenia may be affected by decreased activity of the M1 muscarinic acetylcholine receptor, dysfunction of NMDA glutamatergic neurotransmission, and serotonergic dysregulation. However, the effects of cholinesterase inhibitors, antidepressants, or 5-HT2 antagonists as adjunctive treatments to antipsychotics for cognitive impairments in schizophrenia have been limited (109-113). Approval of antipsychotic drugs with novel mechanisms of action has been rare in recent years despite extensive efforts by investigators. Further investigations are essential to address this issue by identifying new pharmacological targets related to ID in patients with schizophrenia. We suggest that patients without ID should be initially detected and excluded from putative clinical trials of drugs meant to mitigate ID in patients with schizophrenia.

\section{COGNITIVE REMEDIATION}

Cognitive remediation or cognitive rehabilitation interventions are designed to improve cognitive impairments through repeated practice of cognitive tasks and/or strategy training. As the effects of antipsychotics on cognitive impairments in schizophrenia patients have been limited, a number of cognitive remediation programs have been increasingly examined to improve cognitive impairments (114). Randomized controlled studies have shown cognitive remediation to have positive effects on cognitive impairments in patients with first-episode psychosis as well as schizophrenia (114-118). The average effect size was small to moderate at approximately $0.40(114,115)$. Some types of cognitive remediation involve extensive use of computers, while others focus primarily on paper-and-pencil tasks. The Neuropsychological Educational Approach to Remediation (NEAR) is an evidencebased cognitive remediation approach (114). The NEAR program involves a combination of "drill and practice" exercises and teaching strategies to ameliorate cognitive impairments (114). NEAR utilizes commercially available educational software to create a rich learning environment that is intrinsically motivating and rewarding (114). Cognitive remediation interventions are conducted individually or in groups. Although the goal of cognitive remediation is to ameliorate cognitive impairments in patients with schizophrenia, more than $12.0 \%$ of participants dropped out at different points during the program $(114,115)$. Therefore, it may be difficult to generalize a cognitive remediation as a treatment for cognitive impairments in patients with schizophrenia. In addition, it remains unclear whether the improvements are sustained or temporary, although short-term effects of cognitive remediation on cognitive function have been indicated (115). Similar to our proposal regarding the composition of drug trials, we suggest that patients without ID should be initially detected and excluded from clinical trials to develop cognitive remediation programs for patients with schizophrenia.

\section{CONCLUSION}

In this study, we reviewed the literature of ID in patients with schizophrenia. Although intellectual impairments are a core feature of schizophrenia, the effects of antipsychotics and cognitive remediation against those impairments have been limited. We have held several workshops on the brief assessment of ID in schizophrenia to promote the concept of monitoring ID in Japanese patients with schizophrenia. Further studies are warranted to develop novel antipsychotics and cognitive remediation for patients with ID.

\section{AUTHOR CONTRIBUTIONS}

$\mathrm{RH}$ supervised the entire project and was critically involved in the design, analysis, and interpretation of the data. $\mathrm{KO}, \mathrm{CS}$, and TS collected the data, wrote the manuscript, and were responsible for performing the literature review. HF, YY, HY, and MF were heavily involved in the collection of the majority of the data and contributed intellectually to the interpretation of the data. All authors contributed to and have approved the final manuscript. 


\section{FUNDING}

This work was supported by Grants-in-Aid for Scientific Research (B) $(25293250,16 \mathrm{H} 05375)$ and Young Scientists (B) (16K19784) from the Japan Society for the Promotion of Science (JSPS); the Health and Labour Sciences Research Grants for Comprehensive

\section{REFERENCES}

1. Ohi K, Shimada T, Nemoto K, Kataoka Y, Yasuyama T, Kimura K, et al. Cognitive clustering in schizophrenia patients, their first-degree relatives and healthy subjects is associated with anterior cingulate cortex volume. Neuroimage Clin (2017) 16:248-56. doi:10.1016/j.nicl.2017.08.008

2. Simeone JC, Ward AJ, Rotella P, Collins J, Windisch R. An evaluation of variation in published estimates of schizophrenia prevalence from 1990 horizontal line 2013: a systematic literature review. BMC Psychiatry (2015) 15:193. doi:10.1186/s12888-015-0578-7

3. Fujino H, Sumiyoshi C, Sumiyoshi T, Yasuda Y, Yamamori H, Ohi K, et al. Performance on the Wechsler Adult Intelligence Scale-III in Japanese patients with schizophrenia. Psychiatry Clin Neurosci (2014) 68(7):534-41. doi:10.1111/pcn.12165

4. Ohi K, Hashimoto R, Yasuda Y, Fukumoto M, Nemoto K, Ohnishi T, et al. The AKT1 gene is associated with attention and brain morphology in schizophrenia. World J Biol Psychiatry (2013) 14(2):100-13. doi:10.3109/15622975. 2011.591826

5. Fukumoto M, Hashimoto R, Ohi K, Yasuda Y, Yamamori H, UmedaYano S, et al. Relation between remission status and attention in patients with schizophrenia. Psychiatry Clin Neurosci (2014) 68(3):234-41. doi:10.1111/ pcn.12119

6. Ohi K, Hashimoto R, Yasuda Y, Fukumoto M, Yamamori H, UmedaYano S, et al. Influence of the NRGN gene on intellectual ability in schizophrenia. J Hum Genet (2013) 58(10):700-5. doi:10.1038/jhg.2013.82

7. Ohi K, Hashimoto R, Ikeda M, Yamamori H, Yasuda Y, Fujimoto M, et al. Glutamate networks implicate cognitive impairments in schizophrenia: genome-wide association studies of 52 cognitive phenotypes. Schizophr Bull (2015) 41(4):909-18. doi:10.1093/schbul/sbu171

8. Horiguchi M, Ohi K, Hashimoto R, Hao Q, Yasuda Y, Yamamori H, et al. Functional polymorphism (C-824T) of the tyrosine hydroxylase gene affects IQ in schizophrenia. Psychiatry Clin Neurosci (2014) 68(6):456-62. doi:10.1111/pcn.12157

9. Hashimoto R, Noguchi H, Hori H, Ohi K, Yasuda Y, Takeda M, et al. Association between the dysbindin gene (DTNBP1) and cognitive functions in Japanese subjects. Psychiatry Clin Neurosci (2009) 63(4):550-6. doi:10.1111/j.1440-1819.2009.01985.x

10. Kahn RS, Keefe RS. Schizophrenia is a cognitive illness: time for a change in focus. JAMA Psychiatry (2013) 70(10):1107-12. doi:10.1001/ jamapsychiatry.2013.155

11. Green MF, Kern RS, Braff DL, Mintz J. Neurocognitive deficits and functional outcome in schizophrenia: are we measuring the "right stuff"? Schizophr Bull (2000) 26(1):119-36. doi:10.1093/oxfordjournals.schbul.a033430

12. Green MF. What are the functional consequences of neurocognitive deficits in schizophrenia? Am J Psychiatry (1996) 153(3):321-30. doi:10.1176/ ajp.153.3.321

13. Badcock JC, Dragovic M, Waters FA, Jablensky A. Dimensions of intelligence in schizophrenia: evidence from patients with preserved, deteriorated and compromised intellect. J Psychiatr Res (2005) 39(1):11-9. doi:10.1016/j. jpsychires.2004.05.002

14. Kremen WS, Vinogradov S, Poole JH, Schaefer CA, Deicken RF, FactorLitvak P, et al. Cognitive decline in schizophrenia from childhood to midlife: a 33-year longitudinal birth cohort study. Schizophr Res (2010) 118(1-3):1-5. doi:10.1016/j.schres.2010.01.009

15. Meier MH, Caspi A, Reichenberg A, Keefe RS, Fisher HL, Harrington H, et al. Neuropsychological decline in schizophrenia from the premorbid to the postonset period: evidence from a population-representative longitudinal study. Am J Psychiatry (2014) 171(1):91-101. doi:10.1176/appi.ajp.2013. 12111438
Research on Persons with Disabilities from the Japan Agency for Medical Research and Development (AMED); and a grant for Brain Mapping by Integrated Neurotechnologies for Disease Studies (Brain/MINDS) (AMED). The funders had no role in the study design, data collection and analysis, decision to publish, or preparation of the manuscript.

16. Sheitman BB, Murray MG, Snyder JA, Silva S, Goldman R, Chakos M, et al. IQ scores of treatment-resistant schizophrenia patients before and after the onset of the illness. Schizophr Res (2000) 46(2-3):203-7. doi:10.1016/ S0920-9964(00)00034-7

17. Hashimoto R, Ikeda M, Ohi K, Yasuda Y, Yamamori H, Fukumoto M, et al. Genome-wide association study of cognitive decline in schizophrenia. Am J Psychiatry (2013) 170(6):683-4. doi:10.1176/appi.ajp.2013.12091228

18. Fujino H, Sumiyoshi C, Yasuda Y, Yamamori H, Fujimoto M, Fukunaga M, et al. Estimated cognitive decline in patients with schizophrenia: a multicenter study. Psychiatry Clin Neurosci (2017) 71(5):294-300. doi:10.1111/pcn.12474

19. Wechsler D. Wechsler Adult Intelligence Scale. New York: The Psychological Corporation (1955).

20. Wechsler D. Wechsler Adult Intelligence Scale Revised. San Antonio, TX: The Psychological Corporation (1981).

21. Wechsler D. Wechsler Adult Intelligence Scale. 3rd ed. San Antonio, TX: The Psychological Corporation (1997).

22. Wechsler D. WAIS-IV: Wechsler Adult Intelligence Scale. 4th ed. San Antonio, TX: The Psychological Corporation (2008).

23. Sumiyoshi C, Fujino H, Sumiyoshi T, Yasuda Y, Yamamori H, Ohi K, et al. Usefulness of the Wechsler Intelligence Scale short form for assessing functional outcomes in patients with schizophrenia. Psychiatry Res (2016) 245:371-8. doi:10.1016/j.psychres.2016.08.018

24. Girard TA, Axelrod BN, Wilkins LK. Comparison of WAIS-III short forms for measuring index and full-scale scores. Assessment (2010) 17(3):400-5. doi: $10.1177 / 1073191110369763$

25. Blyler CR, Gold JM, Iannone VN, Buchanan RW. Short form of the WAISIII for use with patients with schizophrenia. Schizophr Res (2000) 46(2-3): 209-15. doi:10.1016/S0920-9964(00)00017-7

26. Sumiyoshi C, Uetsuki M, Suga M, Kasai K, Sumiyoshi T. Development of brief versions of the Wechsler Intelligence Scale for schizophrenia: considerations of the structure and predictability of intelligence. Psychiatry Res (2013) 210(3):773-9. doi:10.1016/j.psychres.2013.08.024

27. Patterson TL, Goldman S, McKibbin CL, Hughs T, Jeste DV. UCSD performance-based skills assessment: development of a new measure of everyday functioning for severely mentally ill adults. Schizophr Bull (2001) 27(2):235-45. doi:10.1093/oxfordjournals.schbul.a006870

28. Birchwood M, Smith J, Cochrane R, Wetton S, Copestake S. The Social Functioning Scale. The development and validation of a new scale of social adjustment for use in family intervention programmes with schizophrenic patients. Br J Psychiatry (1990) 157:853-9. doi:10.1192/bjp.157.6.853

29. Nemoto T, Fujii C, Miura Y, Chino B, Kobayashi H, Yamazawa R, et al. Reliability and validity of the Social Functioning Scale Japanese version (SFS-J). Jpn Bull Soc Psychiatry (2008) 17:188-95.

30. Badcock JC, Williams RJ, Anderson M, Jablensky A. Speed of processing and individual differences in IQ in schizophrenia: general or specific cognitive deficits? Cogn Neuropsychiatry (2004) 9(4):233-47. doi:10.1080/ 13546800344000228

31. Dykiert D, Deary IJ. Retrospective validation of WTAR and NART scores as estimators of prior cognitive ability using the Lothian Birth Cohort 1936. Psychol Assess (2013) 25(4):1361-6. doi:10.1037/a0033623

32. Mathias JL, Bowden SC, Barrett-Woodbridge M. Accuracy of the Wechsler test of adult reading (WTAR) and national adult reading test (NART) when estimating IQ in a healthy Australian sample. Aust Psychol (2007) 42:49-56. doi:10.1080/00050060600827599

33. Mullen CM, Fouty HE. Comparison of the WRAT4 reading subtest and the WTAR for estimating premorbid ability level. Appl Neuropsychol Adult (2014) 21(1):69-72. doi:10.1080/09084282.2012.727111

34. Dalby JT, Williams R. Preserved reading and spelling ability in psychotic disorders. Psychol Med (1986) 16(1):171-5. doi:10.1017/S0033291700002609 
35. Amminger GP, Edwards J, Brewer WJ, Harrigan S, McGorry PD. Duration of untreated psychosis and cognitive deterioration in first-episode schizophrenia. Schizophr Res (2002) 54(3):223-30. doi:10.1016/S0920-9964(01)00278-X

36. Schretlen DJ, Cascella NG, Meyer SM, Kingery LR, Testa SM, Munro CA, et al. Neuropsychological functioning in bipolar disorder and schizophrenia. Biol Psychiatry (2007) 62(2):179-86. doi:10.1016/j.biopsych.2006.09.025

37. Matsuoka K, Uno M, Kasai K, Koyama K, Kim Y. Estimation of premorbid IQ in individuals with Alzheimer's disease using Japanese ideographic script (Kanji) compound words: Japanese version of National Adult Reading Test. Psychiatry Clin Neurosci (2006) 60(3):332-9. doi:10.1111/j.1440-1819.2006.01510.x

38. Ohi K, Shimada T, Nitta Y, Kihara H, Okubo H, Uehara T, et al. Specific gene expression patterns of 108 schizophrenia-associated loci in cortex. Schizophr Res (2016) 174(1-3):35-8. doi:10.1016/j.schres.2016.03.032

39. Ohi K, Shimada T, Kihara H, Yasuyama T, Sawai K, Matsuda Y, et al. Impact of familial loading on prefrontal activation in major psychiatric disorders: a near-infrared spectroscopy (NIRS) study. Sci Rep (2017) 7:44268. doi: $10.1038 /$ srep44268

40. Ohi K, Kikuchi M, Ikeda M, Yamamori H, Yasuda Y, Fujimoto M, et al. Polygenetic components for schizophrenia, bipolar disorder and rheumatoid arthritis predict risk of schizophrenia. Schizophr Res (2016) 175(1-3):226-9. doi:10.1016/j.schres.2016.04.009

41. Ohi K, Hashimoto R, Yamamori H, Yasuda Y, Fujimoto M, Umeda-Yano S, et al. The impact of the genome-wide supported variant in the cyclin M2 gene on gray matter morphology in schizophrenia. Behav Brain Funct (2013) 9:40. doi:10.1186/1744-9081-9-40

42. Ohi K, Hashimoto R, Ikeda M, Yamashita F, Fukunaga M, Nemoto K, et al. Genetic risk variants of schizophrenia associated with left superior temporal gyrus volume. Cortex (2014) 58:23-6. doi:10.1016/j.cortex.2014.05.011

43. Morrison G, Sharkey V, Allardyce J, Kelly RC, McCreadie RG. Nithsdale schizophrenia surveys 21: a longitudinal study of national adult reading test stability. Psychol Med (2000) 30(3):717-20. doi:10.1017/S0033291799001920

44. Weickert TW, Goldberg TE, Gold JM, Bigelow LB, Egan MF, Weinberger DR. Cognitive impairments in patients with schizophrenia displaying preserved and compromised intellect. Arch Gen Psychiatry (2000) 57(9):907-13. doi:10.1001/archpsyc.57.9.907

45. Ammari N, Heinrichs RW, Pinnock F, Miles AA, Muharib E, McDermid Vaz S. Preserved, deteriorated, and premorbidly impaired patterns of intellectual ability in schizophrenia. Neuropsychology (2014) 28(3):353-8. doi:10.1037/ neu0000026

46. Kremen WS, Seidman LJ, Faraone SV, Tsuang MT. IQ decline in crosssectional studies of schizophrenia: methodology and interpretation. Psychiatry Res (2008) 158(2):181-94. doi:10.1016/j.psychres.2006.01.022

47. Leeson VC, Sharma P, Harrison M, Ron MA, Barnes TR, Joyce EM. IQ trajectory, cognitive reserve, and clinical outcome following a first episode of psychosis: a 3-year longitudinal study. Schizophr Bull (2011) 37(4):768-77. doi:10.1093/schbul/sbp143

48. Mercado CL, Johannesen JK, Bell MD. Thought disorder severity in compromised, deteriorated, and preserved intellectual course of schizophrenia. J Nerv Ment Dis (2011) 199(2):111-6. doi:10.1097/NMD.0b013e3182083bae

49. Potter AI, Nestor PG. IQ subtypes in schizophrenia: distinct symptom and neuropsychological profiles. J Nerv Ment Dis (2010) 198(8):580-5. doi:10.1097/NMD.0b013e3181ea4e43

50. Weinberg D, Lenroot R, Jacomb I, Allen K, Bruggemann J, Wells R, et al. Cognitive subtypes of schizophrenia characterized by differential brain volumetric reductions and cognitive decline. JAMA Psychiatry (2016) 73(12):1251-9. doi:10.1001/jamapsychiatry.2016.2925

51. Wells R, Swaminathan V, Sundram S, Weinberg D, Bruggemann J, Jacomb I, et al. The impact of premorbid and current intellect in schizophrenia: cognitive, symptom, and functional outcomes. NPJ Schizophr (2015) 1:15043. doi:10.1038/npjschz.2015.43

52. Tandon R, Gaebel W, Barch DM, Bustillo J, Gur RE, Heckers S, et al. Definition and description of schizophrenia in the DSM-5. Schizophr Res (2013) 150(1):3-10. doi:10.1016/j.schres.2013.05.028

53. Palmer BW, Heaton RK, Paulsen JS, Kuck J, Braff D, Harris MJ, et al. Is it possible to be schizophrenic yet neuropsychologically normal? Neuropsychology (1997) 11(3):437-46. doi:10.1037/0894-4105.11.3.437

54. Allen DN, Goldstein G, Warnick E. A consideration of neuropsychologically normal schizophrenia. J Int Neuropsychol Soc (2003) 9(1):56-63. doi:10.1017/ S135561770391006X
55. Lewandowski KE, Sperry SH, Cohen BM, Ongur D. Cognitive variability in psychotic disorders: a cross-diagnostic cluster analysis. Psychol Med (2014) 44(15):3239-48. doi:10.1017/S0033291714000774

56. Seaton BE, Goldstein G, Allen DN. Sources of heterogeneity in schizophrenia: the role of neuropsychological functioning. Neuropsychol Rev (2001) 11(1):45-67. doi:10.1023/A:1009013718684

57. Heinrichs RW, Awad AG. Neurocognitive subtypes of chronic schizophrenia.SchizophrRes(1993)9(1):49-58.doi:10.1016/0920-9964(93)90009-8

58. Hill SK, Ragland JD, Gur RC, Gur RE. Neuropsychological profiles delineate distinct profiles of schizophrenia, an interaction between memory and executive function, and uneven distribution of clinical subtypes. J Clin Exp Neuropsychol (2002) 24(6):765-80. doi:10.1076/jcen.24.6.765.8402

59. Seaton BE, Allen DN, Goldstein G, Kelley ME, van Kammen DP. Relations between cognitive and symptom profile heterogeneity in schizophrenia. J NervMentDis(1999) 187(7):414-9.doi:10.1097/00005053-199907000-00004

60. Goldstein G, Allen DN, Seaton BE. A comparison of clustering solutions for cognitive heterogeneity in schizophrenia. J Int Neuropsychol Soc (1998) 4(4):353-62.

61. Wilk CM, Gold JM, McMahon RP, Humber K, Iannone VN, Buchanan RW. No, it is not possible to be schizophrenic yet neuropsychologically normal. Neuropsychology (2005) 19(6):778-86. doi:10.1037/0894-4105.19.6.778

62. Kremen WS, Seidman LJ, Faraone SV, Tsuang MT. Intelligence quotient and neuropsychological profiles in patients with schizophrenia and in normal volunteers. Biol Psychiatry (2001) 50(6):453-62. doi:10.1016/S00063223(01)01099-X

63. Sullivan PF, Kendler KS, Neale MC. Schizophrenia as a complex trait: evidence from a meta-analysis of twin studies. Arch Gen Psychiatry (2003) 60(12):1187-92. doi:10.1001/archpsyc.60.12.1187

64. Swagerman SC, de Geus EJ, Kan KJ, van Bergen E, Nieuwboer HA, Koenis MM, et al. The computerized neurocognitive battery: validation, aging effects, and heritability across cognitive domains. Neuropsychology (2016) 30(1): 53-64. doi:10.1037/neu0000248

65. Husted JA, Lim S, Chow EW, Greenwood C, Bassett AS. Heritability of neurocognitive traits in familial schizophrenia. Am JMed Genet B Neuropsychiatr Genet (2009) 150B(6):845-53. doi:10.1002/ajmg.b.30907

66. Berrettini WH. Genetic bases for endophenotypes in psychiatric disorders. Dialogues Clin Neurosci (2005) 7(2):95-101.

67. Chen WJ, Liu SK, Chang CJ, Lien YJ, Chang YH, Hwu HG. Sustained attention deficit and schizotypal personality features in nonpsychotic relatives of schizophrenic patients. Am J Psychiatry (1998) 155(9):1214-20. doi:10.1176/ ajp.155.9.1214

68. Posthuma D, de Geus EJ, Boomsma DI. Perceptual speed and IQ are associated through common genetic factors. Behav Genet (2001) 31(6):593-602. doi:10.1023/A:1013345411774

69. Bilder RM, Goldman RS, Robinson D, Reiter G, Bell L, Bates JA, et al. Neuropsychology of first-episode schizophrenia: initial characterization and clinical correlates. Am J Psychiatry (2000) 157(4):549-59. doi:10.1176/appi. ajp.157.4.549

70. Hill SK, Schuepbach D, Herbener ES, Keshavan MS, Sweeney JA. Pretreatment and longitudinal studies of neuropsychological deficits in antipsychotic-naive patients with schizophrenia. Schizophr Res (2004) 68(1):49-63. doi:10.1016/S0920-9964(03)00213-5

71. Hoff AL, Sakuma M, Wieneke M, Horon R, Kushner M, DeLisi LE. Longitudinal neuropsychological follow-up study of patients with firstepisode schizophrenia. Am J Psychiatry (1999) 156(9):1336-41.

72. Green MF. Cognitive impairment and functional outcome in schizophrenia and bipolar disorder. J Clin Psychiatry (2006) 67(Suppl 9):3-8. doi:10.4088/ JCP.1006e12

73. Toulopoulou T, Goldberg TE, Mesa IR, Picchioni M, Rijsdijk F, Stahl D, et al. Impaired intellect and memory: a missing link between genetic risk and schizophrenia? Arch Gen Psychiatry (2010) 67(9):905-13. doi:10.1001/ archgenpsychiatry.2010.99

74. Stefansson H, Ophoff RA, Steinberg S, Andreassen OA, Cichon S, Rujescu D, et al. Common variants conferring risk of schizophrenia. Nature (2009) 460(7256):744-7. doi:10.1038/nature08186

75. O’Donovan MC, Craddock N, Norton N, Williams H, Peirce T, Moskvina V, et al. Identification of loci associated with schizophrenia by genome-wide association and follow-up. Nat Genet (2008) 40(9):1053-5. doi:10.1038/ng.201 
76. Ripke S, Sanders AR, Kendler KS, Levinson DF, Sklar P, Holmans PA, et al. Genome-wide association study identifies five new schizophrenia loci. Nat Genet (2011) 43(10):969-76. doi:10.1038/ng.940

77. Trampush JW, Yang ML, Yu J, Knowles E, Davies G, Liewald DC, et al. GWAS meta-analysis reveals novel loci and genetic correlates for general cognitive function: a report from the COGENT consortium. Mol Psychiatry (2017) 22(3):336-45. doi:10.1038/mp.2016.244

78. Lencz T, Knowles E, Davies G, Guha S, Liewald DC, Starr JM, et al. Molecular genetic evidence for overlap between general cognitive ability and risk for schizophrenia: a report from the Cognitive Genomics consorTium (COGENT). Mol Psychiatry (2014) 19(2):168-74. doi:10.1038/mp.2013.166

79. Weickert TW, Goldberg TE, Egan MF, Apud JA, Meeter M, Myers CE, et al. Relative risk of probabilistic category learning deficits in patients with schizophrenia and their siblings. Biol Psychiatry (2010) 67(10):948-55. doi:10.1016/j.biopsych.2009.12.027

80. Hashimoto R, Ohi K, Yamamori H, Yasuda Y, Fujimoto M, UmedaYano S, et al. Imaging genetics and psychiatric disorders. Curr Mol Med (2015) 15(2):168-75. doi:10.2174/1566524015666150303104159

81. Morita K, Miura K, Fujimoto M, Yamamori H, Yasuda Y, Iwase M, et al. Eye movement as a biomarker of schizophrenia: using an integrated eye movement score. Psychiatry Clin Neurosci (2017) 71(2):104-14. doi:10.1111/ pcn. 12460

82. Yasuyama T, Ohi K, Shimada T, Uehara T, Kawasaki Y. Differences in social functioning among patients with major psychiatric disorders: interpersonal communication is impaired in patients with schizophrenia and correlates with an increase in schizotypal traits. Psychiatry Res (2017) 249:30-4. doi:10.1016/j.psychres.2016.12.053

83. Ohi K, Ursini G, Li M, Shin JH, Ye T, Chen Q, et al. DEGS2 polymorphism associated with cognition in schizophrenia is associated with gene expression in brain. Transl Psychiatry (2015) 5(14):e550. doi:10.1038/tp.2015.45

84. Meltzer HY, Rajagopal L, Huang M, Oyamada Y, Kwon S, Horiguchi M. Translating the N-methyl-D-aspartate receptor antagonist model of schizophrenia to treatments for cognitive impairment in schizophrenia. Int J Neuropsychopharmacol (2013) 16(10):2181-94. doi:10.1017/ S1461145713000928

85. Coyle JT. Glutamate and schizophrenia: beyond the dopamine hypothesis. Cell Mol Neurobiol (2006) 26(4-6):365-84. doi:10.1007/s10571-0069062-8

86. Krystal JH, Anand A, Moghaddam B. Effects of NMDA receptor antagonists: implications for the pathophysiology of schizophrenia. Arch Gen Psychiatry (2002) 59(7):663-4. doi:10.1001/archpsyc.59.7.663

87. Amitai N, Markou A. Disruption of performance in the five-choice serial reaction time task induced by administration of N-methyl-D-aspartate receptor antagonists: relevance to cognitive dysfunction in schizophrenia. Biol Psychiatry (2010) 68(1):5-16. doi:10.1016/j.biopsych.2010. 03.004

88. Pilowsky LS, Bressan RA, Stone JM, Erlandsson K, Mulligan RS, Krystal JH, et al. First in vivo evidence of an NMDA receptor deficit in medication-free schizophrenic patients. Mol Psychiatry (2006) 11(2):118-9. doi:10.1038/ sj.mp. 4001751

89. Akbarian S, Sucher NJ, Bradley D, Tafazzoli A, Trinh D, Hetrick WP, et al. Selective alterations in gene expression for NMDA receptor subunits in prefrontal cortex of schizophrenics. J Neurosci (1996) 16(1):19-30.

90. Wojtalik JA, Smith MJ, Keshavan MS, Eack SM. A systematic and metaanalytic review of neural correlates of functional outcome in schizophrenia. Schizophr Bull (2017) 43(6):1329-47. doi:10.1093/schbul/sbx008

91. Tessier C, Sweers K, Frajerman A, Bergaoui H, Ferreri F, Delva C, et al. Membrane lipidomics in schizophrenia patients: a correlational study with clinical and cognitive manifestations. Transl Psychiatry (2016) 6(10):e906. doi:10.1038/tp.2016.142

92. Schmitt A, Wilczek K, Blennow K, Maras A, Jatzko A, Petroianu G, et al. Altered thalamic membrane phospholipids in schizophrenia: a postmortem study. Biol Psychiatry (2004) 56(1):41-5. doi:10.1016/j.biopsych.2004. 03.019

93. Mizutani Y, Kihara A, Igarashi Y. Identification of the human sphingolipid C4-hydroxylase, hDES2, and its up-regulation during keratinocyte differentiation. FEBS Lett (2004) 563(1-3):93-7. doi:10.1016/S0014-5793(04) 00274-1
94. Omae F, Miyazaki M, Enomoto A, Suzuki M, Suzuki Y, Suzuki A. DES2 protein is responsible for phytoceramide biosynthesis in the mouse small intestine. Biochem J (2004) 379(Pt 3):687-95. doi:10.1042/bj20031425

95. Stip E, Chouinard S, Boulay LJ. On the trail of a cognitive enhancer for the treatment of schizophrenia. Prog Neuropsychopharmacol Biol Psychiatry (2005) 29(2):219-32. doi:10.1016/j.pnpbp.2004.11.004

96. Harvey PD, Keefe RS. Studies of cognitive change in patients with schizophrenia following novel antipsychotic treatment. Am J Psychiatry (2001) 158(2):176-84. doi:10.1176/appi.ajp.158.2.176

97. Woodward ND, Purdon SE, Meltzer HY, Zald DH. A meta-analysis of neuropsychological change to clozapine, olanzapine, quetiapine, and risperidone in schizophrenia. Int J Neuropsychopharmacol (2005) 8(3):457-72. doi:10.1017/ S146114570500516X

98. Remberk B, Namyslowska I, Rybakowski F. Cognition and communication dysfunctions in early-onset schizophrenia: effect of risperidone. Prog Neuropsychopharmacol Biol Psychiatry (2012) 39(2):348-54. doi:10.1016/j. pnpbp.2012.07.007

99. Crespo-Facorro B, Rodriguez-Sanchez JM, Perez-Iglesias R, Mata I, Ayesa R, Ramirez-Bonilla $M$, et al. Neurocognitive effectiveness of haloperidol, risperidone, and olanzapine in first-episode psychosis: a randomized, controlled 1-year follow-up comparison. J Clin Psychiatry (2009) 70(5):717-29. doi:10.4088/JCP.08m04634

100. Cuesta MJ, Jalon EG, Campos MS, Peralta V. Cognitive effectiveness of olanzapine and risperidone in first-episode psychosis. Br J Psychiatry (2009) 194(5):439-45. doi:10.1192/bjp.bp.108.055137

101. Fujimoto M, Hashimoto R, Yamamori H, Yasuda Y, Ohi K, Iwatani H, et al. Clozapine improved the syndrome of inappropriate antidiuretic hormone secretion in a patient with treatment-resistant schizophrenia. Psychiatry Clin Neurosci (2016) 70(10):469. doi:10.1111/pcn.12435

102. Yamaki N, Hishimoto A, Otsuka I, Sasada T, Boku S, Saito T, et al. Optimizing outcomes in clozapine rechallenge following neutropenia using human leukocyte antigen typing: a case report. Psychiatry Clin Neurosci (2017) 71(4):289-90. doi:10.1111/pcn.12505

103. Meltzer HY, Massey BW. The role of serotonin receptors in the action of atypical antipsychotic drugs. Curr Opin Pharmacol (2011) 11(1):59-67. doi:10.1016/j.coph.2011.02.007

104. Minzenberg MJ, Poole JH, Benton C, Vinogradov S. Association of anticholinergic load with impairment of complex attention and memory in schizophrenia. Am J Psychiatry (2004) 161(1):116-24. doi:10.1176/appi. ajp.161.1.116

105. Ogino S, Miyamoto S, Tenjin T, Kitajima R, Ojima K, Miyake N, et al. Effects of discontinuation of long-term biperiden use on cognitive function and quality of life in schizophrenia. Prog Neuropsychopharmacol Biol Psychiatry (2011) 35(1):78-83. doi:10.1016/j.pnpbp.2010.08.030

106. Ogino S, Miyamoto S, Miyake N, Yamaguchi N. Benefits and limits of anticholinergic use in schizophrenia: focusing on its effect on cognitive function. Psychiatry Clin Neurosci (2014) 68(1):37-49. doi:10.1111/pcn.12088

107. Hindmarch I. Cognitive toxicity of pharmacotherapeutic agents used in social anxiety disorder. Int J Clin Pract (2009) 63(7):1085-94. doi:10.1111/j. 1742-1241.2009.02085.x

108. Kitajima R, Miyamoto S, Tenjin T, Ojima K, Ogino S, Miyake N, et al. Effects of tapering of long-term benzodiazepines on cognitive function in patients with schizophrenia receiving a second-generation antipsychotic. Prog Neuropsychopharmacol Biol Psychiatry (2012) 36(2):300-6. doi:10.1016/j. pnpbp.2011.11.008

109. Lee SW, Lee JG, Lee BJ, Kim YH. A 12-week, double-blind, placebocontrolled trial of galantamine adjunctive treatment to conventional antipsychotics for the cognitive impairments in chronic schizophrenia. Int Clin Psychopharmacol (2007) 22(2):63-8. doi:10.1097/YIC.0b013e3280117feb

110. Akhondzadeh S, Gerami M, Noroozian M, Karamghadiri N,Ghoreishi A, Abbasi SH, et al. A 12-week, double-blind, placebo-controlled trial of donepezil adjunctive treatment to risperidone in chronic and stable schizophrenia. Prog Neuropsychopharmacol Biol Psychiatry (2008) 32(8):1810-5. doi:10.1016/j.pnpbp.2008.08.001

111. Ribeiz SR, Bassitt DP, Arrais JA, Avila R, Steffens DC, Bottino CM. Cholinesterase inhibitors as adjunctive therapy in patients with schizophrenia and schizoaffective disorder: a review and meta-analysis of the literature. CNS Drugs (2010) 24(4):303-17. doi:10.2165/11530260-000000000-00000 
112. Delle Chiaie R, Salviati M, Fiorentini S, Biondi M. Add-on mirtazapine enhances effects on cognition in schizophrenic patients under stabilized treatment with clozapine. Exp Clin Psychopharmacol (2007) 15(6):563-8. doi:10.1037/1064-1297.15.6.563

113. Poyurovsky M, Koren D, Gonopolsky I, Schneidman M, Fuchs C, Weizman A, et al. Effect of the 5-HT2 antagonist mianserin on cognitive dysfunction in chronic schizophrenia patients: an add-on, double-blind placebocontrolled study. Eur Neuropsychopharmacol (2003) 13(2):123-8. doi:10.1016/ S0924-977X(02)00155-4

114. Hodge MA, Siciliano D, Withey P, Moss B, Moore G, Judd G, et al. A randomized controlled trial of cognitive remediation in schizophrenia. Schizophr Bull (2010) 36(2):419-27. doi:10.1093/schbul/sbn102

115. Wykes T, Huddy V, Cellard C, McGurk SR, Czobor P. A meta-analysis of cognitive remediation for schizophrenia: methodology and effect sizes. Am J Psychiatry (2011) 168(5):472-85. doi:10.1176/appi.ajp.2010.10060855

116. Wexler BE, Bell MD. Cognitive remediation and vocational rehabilitation for schizophrenia. Schizophr Bull (2005) 31(4):931-41. doi:10.1093/schbul/ sbi038
117. Wykes T, Reeder C, Landau S, Everitt B, Knapp M, Patel A, et al. Cognitive remediation therapy in schizophrenia: randomised controlled trial. $\mathrm{Br}$ J Psychiatry (2007) 190:421-7. doi:10.1192/bjp.bp.106.026575

118. Revell ER, Neill JC, Harte M, Khan Z, Drake RJ. A systematic review and meta-analysis of cognitive remediation in early schizophrenia. Schizophr Res (2015) 168(1-2):213-22. doi:10.1016/j.schres.2015.08.017

Conflict of Interest Statement: The authors declare that the research was conducted in the absence of any commercial or financial relationships that could be construed as a potential conflict of interest.

Copyright (c) 2017 Ohi, Sumiyoshi, Fujino, Yasuda, Yamamori, Fujimoto, Sumiyoshi and Hashimoto. This is an open-access article distributed under the terms of the Creative Commons Attribution License (CC BY). The use, distribution or reproduction in other forums is permitted, provided the original author(s) or licensor are credited and that the original publication in this journal is cited, in accordance with accepted academic practice. No use, distribution or reproduction is permitted which does not comply with these terms. 